\title{
The Role of Social Work Practice in Cross - Cultural Interview
}

\author{
Konstantina Sklavou \\ Social Worker, Pedagogue \\ Department of Psychiatry for Children and Adolescents \\ Sismanoglio Hospital \\ Athens Greece
}

\begin{abstract}
In cross-cultural interview, difficulties often arise, and derive from the fact that, social workers and interviewees come from much different worlds, and some major sub-cultural differences- such as socio-economic group, race or ethnicity, gender, age and sexual orientation - may differentiate the interviewer from the interviewee, and consequently, increase social distance and limit understanding, between them. The purpose of this article is to point out the meaning of counseling, in social work practice, and in addition to isolate and clarify these differences that may be of crucial importance, on how the interview will be conducted between a social worker and an individual from a different race. During the interview, there is, however, a need for balance, in assessing the importance of these key-identifying characteristics. Despite the great number of books and articles referring to racial and ethnic data collection, social workers, rarely, discuss the explicit relevance of these information, in order to conduct an interview.
\end{abstract}

Keywords: cross cultural social work, social work interview, racial and ethnic differences.

\section{Introduction}

The influx -in particular, unpredicted and uncontrolled - of foreign population in each host country and host society, is an important condition, which is translated in multiple needs, such as highlighting the weakness of national and welfare mechanisms, polarizing inclinations and discomfort, and generally a state of imbalance, which requires multifocal intervention. Substantial involvement with various minority groups, should be a realistic goal, rather than a desired status (Anagnostopoulos, 2016). Cross-cultural social work, is a golden ticket to this, as it approaches by definition minority populations, and has the dynamic to schedule a multitude of tasks relevant to them (Kadushin \& Kadushin, 1997).

On this basis, the framework, into which the professional relationship and the relevant ambiance will be developed, with the social worker and the interviewee, as interactive parts and as exponents of different ethnocultural and religious heritage, comes out as a vital component for a correct and successful, or nonsuccessful way of the counseling process (Jandt, 2010). Each side is not only a physical presence but also a bearer of a mixture of perceptions, values, attitudes, that interfere and affect the whole interaction. And while for the interviewee, the control of effect of that mixture, is not, and cannot be the desideratum...for the specialist definitely is... as the status and the project he is called upon to perform, do not allow him to be prejudiced on any basis of familiarized meanings. Certainly, that doesn't mean that he must decline those meanings, but on the contrary, he should be aware of them, just like of his temperament and identity, and at a later stage, being able to realize the interviewee's concerns, and evaluate any differences that will be found (Corey, 2009). For such purposes, among any personal fortification, there is also a need for an equivalent fortification, in terms of knowledge, that of fundamental elements of each culture and the characteristics of its people, as some of those representatives a specialist will be asked to cooperate with. This is an extremely essential element, with increased chances of effectiveness, not only for the correct course of the whole procedure from start to finish, but also for the operational preparation, installation and fulfillment of this procedure, already from its initial stage. Moreover, a wider adaptation to the interviewee's needs, does not include only theoretical orientation and methodology of the expert, but also the reassurance of compatibility to some basic textural issues. Therefore, a disposition of the technique of communication, in the native language, and in the socio-educational level of the interviewee, along with a delimitation of the framework of cooperation, with a parameter of the perceptual and interpretative system of it, is definitely an indisputable necessity (Ferri, 2018). 
When it comes to interactions with individuals who share a common culture or have the same ethnic origin, elements that seem to be simple and possibly given, should not be defined as such, in cross cultural practice. The time and space in which the meeting will be held, as well as the physical interaction therein, require a specific delineation and consideration, with respect to the worldview of the individual. The value system and the ideological codes of a person who is involved in the treatment, may cause practical issues, such as diligence and typical response, as they are defined within the therapeutical contract. In addition, in a culture A, a fact that can be interpreted as a sign of courtesy or interest by the therapist, in a culture B, could be a cause of misunderstanding, insult or awkwardness; or vice versa a thrifty practice of the interviewee's side, could simply reflect the way of acting, in which he is familiar with, and is not necessarily translated in some kind of denial or indifference, towards the whole procedure (Kadushin \& Kadushin, 1997). In some cases, even the substantial consent of taking part in the therapeutic practice, on the basis of recognizing its value, is under negotiation, since the whole process may not be provided for, or opposed to, the culture of the servant (Theodorou \& Sklavou, 2015). Finally, on the opposite end of a possible resistance, from the interviewee's side, there is a strong tendency to adhere to the specialist in the sense of placing hopes in him, in order to find and ensure an exit to the problematic situation.

\section{Dimensions of Counseling in the Field of Social Work}

Consultative social work is not necessarily translated into a dry procedure of counseling and advocacy to the interviewee, from the specialist, since this would primarily involve an unequal relationship, on a controlling basis. Definitely a required master in professional knowledge and speech of the expert -attributive features of his work object- may ensure a position of power, but definitely do not refer to a vertical hierarchical communication. As is apparent from the etymological analysis of the term, counseling reflects thoughts, that are shared with someone else on an equal basis. It is a dialectical relationship, with an evolving nature, and with the aim to motivate the individual and change his life. An essential condition for the development and the groundings of such a dynamic, is firstly the intentional involvement of the interviewee with a relevant formulation for a specific request per case, which may not necessarily match with the real, and sometimes dormant problem (Corey, 2012). On the contrary, according to Feltham and Horton (2001), there is a need for provision in counseling services by experts, in a disciplined, professional and formal, base. Due to multiplicity and complexity of the profession of social work, as it derives from the current socio-economic-historical needs, the counseling process in its genuine dimension, is performing several times in a parallel, or after the settlement of pressures and emergency situations related to the interviewee (such as the cover of basic needs, unemployment, health problems, crisis situations, and so on). As a result, the role of the social worker in counseling, is to help individuals to work on data and define themselves in a way of action, that is compatible with their capabilities, and last but not least the commitment to admit and take responsibility of any upcoming consequences. Of course, in particular cases of vulnerable people or children, the social worker is informed on any rights and obligations, but when it is necessary, he will take action, and make a decision against the desires and aspirations of these people (Moss, 2008). With regard to professional occupation with ethnic groups, cross cultural counseling has a balancing role in the process of adaptation to the new society, and is an ultimate functional tool for the social worker (Sklavou, 2008).

\section{Axes of needs and the role of Intercultural Counseling}

The transformation of a society from an intercultural, into a multicultural one, is certain and obvious as soon new issues, directly connected to the new social reality, require adjustments. Individuals from different cultures bring out a unique range of needs, directly originated from migrating till settling in an unknown host society; there are needs that should be handled by professionals, through the services that the individuals will be addressed. In such an environment, the reinforcement of the provided social services, and the targeted and sensitized action of the social scientists and in particular of the social workers, constitute a structural factor, for the implementation of a social stabilization plan. One of the most important pieces of the work is that, of cultural shock where the separation from the home ground, and the pressure for adaptation to a new one, creates feelings of anxiety, disorientation and confusion, with a direct impact, both on the individual's self-image and self-esteem (Kanel, 2012). In that case a social worker via cross cultural counseling could have a beneficial role, in many ways. Firstly, by pointing out the universality of migration, in order to alleviate any feelings of inadequacy and guilt, and by making mention of the local community of compatriots, which will assist the individual, through the exchange of experience, in order to understand that he is not alone, and therefore to set realistic targets of adjustment. 
So, a language learning program and an encouraging interaction with people from the host society, are considered to be beneficial and necessary elements of work (Zapf, 1991). Feelings of rejection, anxiety and uncertainty are very likely to occur in individuals, for various reasons. The hostile or restrained attitudes of the natives, based on the sense of threat from the foreign element, are one of these reasons. Another source of insecurity and concern is that of property, or personal belongings, which offer some kind of fortification and constitute a source of stability, especially for children (Kokonya et al., 2014). The importance of managing stress and other psychological issues, such as: a smooth transition from one cultural background to another, from a familiar environment to a wider social one, and the management of any pressure derived from the extra burden of learning a new language, new skills, values and behavioral rules in the host country, should not be neglected (Krečič Javornik, 2009). In any case, the above issues require monitoring and equivalent management. A nuclear dimension of counseling process towards minority populations, must be the acknowledgement of the value of diversity and a relative awareness, in order to ensure a sense of security and respect, and of course, inter alia, the prevention and suppression of the phenomenon of social exclusion (Hall \& Reed Hall, 1990). These objects of study have already moved through the desocialization phase and afterwards they are asked to go through the resocialisation phase, a highly demanding process, that without the proper co-ordination, no social integration-resolution can be achieved.

\section{Cultural competence as a skill of a social worker}

In a multicultural society, the use of the word "different", highlights the need for cultural competence, as a prerequisite of the specialist, for an efficient function, defined as: "The ability to involve in actions, or create conditions that maximize the best possible progression of the customer and the customer's systems" (Sue, 2006: 29).

This concept consists of three structural elements: a) the personal perceptions and attitudes of the expert, influenced-configured, to a great extent, by his cultural burden, b) deep knowledge on the cultural values and forms of different cultural populations and their importance and, c) the ability to adapt to data and to the preparation of any case of intervention (Sue, 2006). It is essentially a fundamental goal with the characteristic of a changing nature process - rather than a static situation, that professionals can easily ensure.

Since cultural competence is mentioned, there should be a special reference to the value of effective communication, and the variables that will be proved useful for this accomplishment. The issue of ensuring the linguistic dimension of communication, certainly, is a top priority (Parry, 2004). The conformation of the linguistic field, based on the mother tongue of the interviewee and ensured by a good knowledge of the spoken language by the social worker, or by an interpreter (usually a compatriot of the former), is defined as a necessary condition (an adequate knowledge of language, dialect, pronunciation and a wider knowledge on the cultural burden and on behavioral manners or even of the same sex with the interviewee, many times is decisive for correct or incorrect communication). One of the most important challenges, as far as communication is concerned, between individuals from different cultural backgrounds, is to clarify the level of content - as to the density of meaning - of each culture, for an appropriate case-by-case adjustment. The content of the messages transmitted per culture, varies, according to a high and low context (Hall \& Reed Hall, 1990), on the basis, that in some countries basic information's are rather broadly familiarized, so they do not turn to explanations, while in other countries, is a necessity, since they do not share common codes; instead they customize functions depending on the given circumstances. Because of this, the counseling process reflects the need for relevant knowledge from the specialist, in order to ensure an unobstructed, balanced and integrated -in terms of meanings- communication concept. Characteristically, when communication is conducted with participants of different contents, it requires great attention to coordinate the incoming information, by the social worker; people from high-content cultures may not receive in a positive way, a detailed apposition of information, while on the other hand, a nonexplanatory practice may work for them, up to chaotic (Samovar et al., 2010). It is equally necessary, to define non-verbal communication, and focus on the texture messages, emitted from the interviewee, as it is an entire system that reflects thoughts, beliefs, moral and cultural commitments, or codes of behavior (Sadri \& Flammia, 2011). These are mainly unconscious, spontaneous expressions, that reaches a wide range of elements, such as body language (gestures, body posture, eye contact), physical distance and (contact) between the two sides, the perception of time, the rhythm and intensity/ tone of speech (Kottler \& Montgomery, 2011). Of particular importance, are those, that are emitted by the specialists, which vary during the scale of communication, in kind and intensity; these are conscious and non-conscious responses, to what the specialists receive, with the relative influence on a case-by-case ground (Gregoire \& Junkers, 2007) . 
The confrontational internal situation of most of the interviewees leaves no space for that kind of mistakes during the procedure. The social worker, must ensure an equal relationship between himself and the interviewee, and clearly understand, that he possesses specialized knowledge and not disregard the life experience of the latest person since he will feel that his own load is respected, that is really an encouraging fact.

\section{Conclusion}

It is clear, that any proficiency in intercultural counseling, conquered by a professional social worker, requires a similar effort for further development and improvement. Efforts made in order, to fight against the lack of knowledge, and to raise awareness of how to manage situations that include the term 'different', are of high importance, as they can help to avoid racist or even discriminatory attitudes towards the people they serve. The specificity and the demanding nature of humanitarian professions and the aggregative character they reflect on the psychological content of professionals, states the need for supervision. Cooperation with individuals from different backgrounds, implies that a lot of issues should be internally negotiated by the professional, such as the management of the developing relationship (proper distribution of roles and regulation of authority /authentic), but also to what the term 'different' generally implies.

The reception and integration of individuals, who are called upon to adapt to a new country and at the same time to be physically and emotionally removed from their old cultural environment, within the counseling process, must be implemented under co-ordinated conditions and trained professionals, who accept diversity, without underlining the word 'difference' as reprehensible. Counseling, as a relationship of interaction and cognitive transaction between two parts, is an instrumental factor to the type of communication and the course of the professional relationship, mainly for those working with ethnic groups.

\section{Bibliography}

Anagnostopoulos, D. (2016). Migration Mental Health Issues in Europe: the case of Greece. Eur Child Psychiatry, 25: 119 - 122.

Bosswick, W. \& Heckmann, F. (2006). Integration of migrants: Contribution of local and regional authorities. Ireland: European Foundation for the Improvement of Living and Working Conditions.

Bryan, W. (2007). Multicultural Aspects of Disabilities: A Guide to Understanding And Assisting Minorities in Rehabilitation Process (2nd ed.). Illinois: Charles C Thomas Publisher Ltd Springfield.

Corey, G. (2009). The Art of Integrative Counseling (3rd ed.). U.S.A.: Brooks/Cole, Cengage Learning.

Corey, G. (2012). Theory and Practice of Group Counseling (8th ed.). U.S.A.: Brooks/Cole, Cengage Learning.

Ferri, G. (2018). Intercultural Communication. Critical Approaches and Future Challenges. USA: Palgrave Macmillan.

Gregoire, J. \& Junkers, C. (2007). The counselor's companion: what every beginning counselor needs to know. New Jersey: Lawrence Erlbaum Associates, Inc., Publishers.

Haley, J. \& Richeport-Haley, M. (2007). Directive Family Therapy. New York: The Haworth Press, Inc.

Hall, E. \& Reed Hall, M. (1990). Understanding cultural differences. Germans, French and Americans. U.S.A.: Intercultural Press.

Jandt, F. (2010). An Introduction to Intercultural Communication: Identities in a Global Community (6th ed.). U.S.A.: SAGE Publications, Inc.

Jones-Smith, E. (2012). Theories of Counseling and Psychotherapy: An Integrative Approach. U.S.A.: SAGE Publications, Inc.

Kadushin, A., Kadushin, G. (1997). The Social Work Interview. A Guide for Human Service Professionals. 4th ed. New York: Columbia University Press.

Kanel, K. (2012). A Guide to Crisis Intervention (4th ed.). U.S.A.: Brooks/Cole, Cengage Learning.

Kokonya, D.A., Kuria, W.M., Ohgecha, F.A., Mburu, J.M., Ndetei, D.M. (2014). Complex Post Traumatic Stress Disorder (PTSD) in Defilement: Case Report. Open Journal of Psychiatry, 4, 176 - 181.

Kottler, J. \& Montgomery, M. (2011). Theories of Counseling and Therapy: An Experiential Approach (2nd ed.). U.S.A.: SAGE Publications, Inc.

Krečič Javornik, M. (2009). Intercultural Counseling as a Current Issue and What Makes a Competent Intercultural Counselor. Informatologia, 42 (1), 45-50. 
Lum, D. (2011). Culturally Competent Practice: A Framework for Understanding Diverse Groups and Justice Issues (4th ed.). U.S.A.: Brooks/Cole Cenage Learning.

Moran, R., Harris, P. \& Moran, S. (2011). Managing Cultural Differences: Leadership Skills and Strategies for Working in a Global World (8th ed.). Oxford: Elsevier Inc.

Moss, B. (2008). Communication Skills for Health and Social Care. London: SAGE Publications, Ltd.

Neukrug, E. (2011). Counseling Theory and Practice. U.S.A.: Brooks/Cole, Cengage Learning.

Parry, I. (2004). Foundations of Intercultural Communication. In: Tjale, A. \& De Villiers, L. (Eds.). Cultural Issues in Health and Health Care, (pp. 106-133). Cape Town: Juta and Co Ltd.

Sadri, H. \& Flammia, M. (2011). Intercultural Communication: A New Approach to International Relations and Global Challenges. New York: The Continuum International Publishing Group.

Samovar, L., Porter, R. \& McDaniel, E. (2010). Communication Between Cultures (7th ed.). U.S.A.: Wadsworth, Cengage Learning.

Sapp, M. (2009). Psychodynamic, Affective, and Behavioral Theories to Psychotherapy. Illinois: Charles C Thomas Publisher Ltd Springfield.

Schneider Corey, M. \& Corey, G. (2011). Becoming a Helper (6th ed.). U.S.A.: Brooks/Cole, Cengage Learning.

Sharf, R. (2011). Theories of Psychotherapy \& Counseling: Concepts and Cases. U.S.A.: Brooks/Cole, Cengage Learning.

Sklavou, K. (2008). Introduction to Intercultural Counseling. In Sklavou, K. (Eds.). Manual of Intercultural Counseling. Greek Council for Refugees (pp. 19-39). Athens: Papazisis.

Sue, D. (2006). Multicultural Social Work Practice. New Jersey: John Wiley \& Sons, Inc.

Thedorou, V., Sklavou, K. (2015). Clinical Social Work involving foreigner adults facing psychiatric disorders. In Kounti K., Tzedaki M., Passa M. (Eds.), The Contribution of Social Work to Psychiatric Treatment (pp. 403-409). Athens: Scientific Publications, Parisianou SA. 